\title{
AVALIAÇÃO DO RESULTADO DA AUDITORIA CLÍNICA DE IDENTIFICAÇÃO DOS PACIENTES EM UMA REDE DE HOSPITAIS PRIVADOS
}

Autores: Angela Zerbielli, Helidea de Oliveira Lima, Deborah Simões, Fernanda Rodrigues, Thamara Petrella. Instituição: Rede D’Or São Luiz

Introdução: Erros de identificação do paciente podem ocorrer, desde a admissão até a alta do serviço, em todas as fases do diagnóstico e do tratamento. Alguns fatores podem potencializar os riscos na identificação do paciente como: estado de consciência do paciente, mudanças de leito, setor ou profissional dentro da instituição e outras circunstâncias no ambiente. (Ministério da Saúde, 2013)

Frente a importância da identificação correta para redução de riscos e mitigação de eventos adversos de trocas de pacientes a Organização Mundial de Saúde priorizou algumas ações dentre elas a identificação do paciente como estratégia internacional para segurança do paciente (Meta 1).

Objetivo: Com este estudo espera-se mensurar a eficácia das ações propostas e implementadas no Protocolo de Segurança da Identificação do Paciente.

Metodologia: Foram avaliados 600 pacientes nos setores de Pronto Socorro Adulto, Unidade de Internação, Maternidade e Unidade de Terapia Intensiva. O período de análise foi de junho a agosto de 2018. O estudo foi realizado em 30 hospitais privados pertencentes a uma rede com atuação nos estados de São Paulo, Rio de Janeiro, Pernambuco e Maranhão.

A avaliação foi realizada considerando os seguintes momentos no mesmo paciente: se o paciente estava com a pulseira de identificação legível (contendo os dois marcadores padronizados na instituição), se todos os impressos do prontuário continham etiquetas ou identificação completa (no caso de registro manual), se os rótulos das medicações preparadas e encontravam-se devidamente identificados e observação direta para verificar se durante a administração do medicamento o colaborador confirmava a identificação do paciente que confirmasse seu nome completo e data de nascimento e conferindo simultaneamente com a pulseira) ou avaliando o relato do próprio paciente da checagem de nome completo e data de nascimento antes de qualquer intervenção diagnóstica, terapêutica ou medicamentosa.

Resultados: Para a construção do resultado - taxa de adesão à identificação correta - foi considerado conforme somente os pacientes que tiveram as três etapas realizadas adequadamente. A média geral da taxa de adesão à identificação correta foi de $58 \%$. A maior oportunidade de melhoria identificada foi com relação aos documentos de prontuário com preenchimento incompleto, nos casos de preenchimento manual do registro e na interface com serviços terceiros, cuja política de identificação era divergente a praticada pelo hospital.

Considerações finais: Estudos comprovam que a adesão aos protocolos que objetivam as metas de segurança tem impacto significativo na redução de eventos adversos. A partir do lançamento do Programa Nacional de Segurança do Paciente as instituições foram convidadas a reforçar os Protocolos de Segurança, mas percebe-se que ainda são necessários ações de melhoria.

Com base nos resultados identificados cada hospital desenvolveu ações de acordo com os achados da auditoria clínica, que terão sua efetividade verificada num ciclo de auditoria, previsto para dezembro de 2018.

Referência Bibliográfica: BRASIL. MINISTÉRIO DA SAÚDE. Programa Nacional de Segurança do Paciente: protocolo de identificação do paciente. PROQUALIS. Maio de 2013. Disponível em:

<http://portalsaude.saude.gov.br/portalsaude/arqu ivos/pdf/2013/Mai/06/protocolos_CP_n6_2013.pd f> Acesso em: 14 Outubro 2018 